\title{
多種粒子を含む懸濁液中での湿式造粒の検討
}

\section{Wet Agglomeration in a Suspension of Particles of Multiple Materials}

\author{
高瀬 均, 小島 明倫 \\ Hitoshi Takase, Akimichi Kojima
}

Received 16 April 2001 ; Accepted 11 July 2001

Wet agglomeration was investigated in a suspension of particles of polar materials, soda-lime glass and calcium carbonate, and nonpolar material, polyethylene, using a nonpolar bridging liquid, dodecane. $10^{-2} \mathrm{~mol} / l-\mathrm{NaCl}$ aqueous solution was used as a dispersion medium, and sodium oleate or dodecylamine hydrochloride was added to it as an additive surface active agent. Adsorption of surface active agent on particles of soda- lime glass and calcium carbonate at an appropriate value improved the wettability of particles to dodecane, and therefore facilitated the wet agglomeration of particles. Wettability of polyethylene particle to dodecane was good without surface active agent. When the concentration of additive surface active agent was less than $10^{-3} \mathrm{~mol} / l$, the surface active agent did not affect the wettability of polyethylene particle to dodecane. Selective wet agglomeration was successfully performed in a suspension of multiple materials by controlling the adhesion tension of dodecane on each particle. Separation of each particle from suspension was carried out well by taking advantage of the selective wet agglomeration.

Key Words : Wet agglomeration, Contact angle, Adhesion tension, Surface treatment, Particle- Particle separation

\section{1. 緒言}

湿式球形造粒において，造粒現象が起こる主たる原 因は，架橋液体の㦟濁粒子間への液体架橋により発生 する毛管吸引王の働きによる造粒粒子内凝集力であ る $^{1 \sim 4)}$ 。毛管吸引匨が造粒粒子内で凝集力として働く ためには, 架橋液体の固体粒子表面に対する接触角が $90^{\circ}$ 未満となる必要がある。すなわち, 湿式球形造 粒は固体粒子表面に対する架橋液体の濡れ性により強 く支配される。この需れ性を，粒子および架橋液体滴 の表面の改質により任意に制御できれば，希望する㦟 濁粒子のみからなる造粒粒子の形成, すなわち選択的 造粒が可能となる。

これまで湿式球形造粒に関して多くの研究がなされ ているが，そのほとんどは 1 種類の試料粒子を用いて の造粒粒子製造 ${ }^{1.5 ~ 7)}$ に関するものである。その他と

\footnotetext{
APT2000（2000年12月，バンコク（タイ））で発表

富山大学工学部物質生命システム工学科

（テ930-8555富山市五福3190）TEL 076-445-6830

Department of Material Systems Engineering and Life

Science, Toyama University

(3190 Gofuku, Toyama 930-8555)
}

しては, 湿式球形造粒法は低品位炭の脱灰操作 ${ }^{8 \sim 10}$ にも利用されている。脱灰操作は，低品位炭を微粉砕 して得られる石炭可燃部粒子と兏分粒子の 2 種類の粒 子が眯濁した液中での， 1 種粒子の選択的造粒と言え る。しかし，選鉱分野における他の数例を除いて，他 分野において選択的湿式造粒法が多種類の粒子を含む 㦟濁液中での成分分離操作に適用された例はあまり見 られないようである。選択的湿式造粒は，粒子径や密 度の差, 磁気力などを利用しても分離が困難な微粒子 混合物の分離操作に特に有効と考えられる。

界面の濡れ性の違いを利用した㦟濁微粒子の分離法 の他の有力な方法としては, 浮選がある。浮選では, 水中で目的粒子表面が捕収剂により疎水化され，これ を気泡に付着させて他の粒子と分離される。気泡は浮 上して液面でフロスを形成し，このフロスより高濃度 の目的粒子が得られる。湿式球形造粒法による選択的 造粒を浮選と比較すると, 以下のことが言える。選択 的造粒の長所としては，被分離粒子が粒子径がより增 大した造粒粒子として得られることから, 被分離粒子 の分散媒中からの回収が容易であること, および造粒

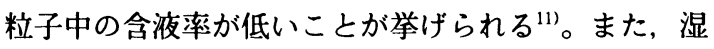


Table 1 Properties of raw particles

\begin{tabular}{lcccc}
\hline \multicolumn{1}{c}{ Raw particle } & $\begin{array}{c}\text { Affinity for } \\
\text { water }\end{array}$ & $\begin{array}{c}\zeta \text {-potential in } 10^{-2} \mathrm{~mol} / l- \\
\mathrm{NaCl} \text { aq. soln. }(\mathrm{mV})\end{array}$ & $\begin{array}{c}d_{\mathrm{p} 50} \\
(\mathrm{~m})\end{array}$ & $\begin{array}{c}\rho_{\mathrm{p}} \\
\left(\mathrm{kg} / \mathrm{m}^{3}\right)\end{array}$ \\
\hline Soda-lime glass & Hydrophilic & -85.8 & $1.86 \times 10^{-5}$ & $2.39 \times 10^{3}$ \\
Calcium carbonate & Hydrophilic & 31.8 & $9.20 \times 10^{-6}$ & $2.72 \times 10^{3}$ \\
Polyethylene & Hydrophobic & -84.3 & $2.15 \times 10^{-5}$ & $9.40 \times 10^{2}$ \\
\hline
\end{tabular}

式球形造粒法の装置形態は浮選に比較して単純であ り, 密閉系中にも装置を組み込める利点がある。一 方, 選択的造粒の短所は, 所定量の架橋液体が必要な ことであり，場合によっては分離粒子の純度を上げる ため, 造粒粒子中からの架橋液体の除去が必要となる ことも有りうる。しかし, 造粒粒子からの架橋液体の 回収と再利用が可能となるシステムが構筑されれば, このような短所も改善されると考えられる。

このような特徴を持つ選択的湿式造粒による混合微 粒子群の分離は, より広い分野での様様な物質の分離 操作に利用できると考えられる。本研究では, 湿式球 形造粒法 (以後, 湿式造粒法と呼ぶ) により材質の異 なる 3 種類の粒子を含む㦟濁液中で選択的造粒を行 いここれ及ぼす個個の暍濁粒子の架橋液体に対する 濡れ性の影響について検討した。悡濁粒子の架橋液体 に対する濡れ性を, 分散媒中に添加した界面活性剂の 懸濁粒子および架橋液体滴への吸着により変化させ た。

\section{2. 実験装置および方法}

\section{1 湿式造粒}

\section{1.1 試料粒子および分散媒}

湿式造粒を，界面物性がそれぞれ異なる極性物質の ソーダ石灰ガラス粒子 (以後, ガラス粒子と呼ぶ),

炭酸カルシウム粒子, 無極性物質のポリエチレン粒子 を用いて行った。各試料粒子の物性を Table 1 に, 遠 心沈降式粒度分布測定装置 (島津製作所製, SA-CP3) で測定した粒子径分布を Fig. 1 に示す。ガラス粒子, ポリエチレン粒子はほほ球形粒子であり, 炭酸カルシ ウム粒子は非球形粒子である。分散媒として $10^{-2}$ $\mathrm{mol} / l-\mathrm{NaCl}$ 水溶液を用い, これにアニオン性界面活 性剂であるオレイン酸ナトリウム $\left(\mathrm{C}_{17} \mathrm{H}_{33} \mathrm{COONa}\right)$, またはカチオン性界面活性剂であるドデシルアミン塩 酸塩 $\left(\mathrm{CH}_{3}\left(\mathrm{CH}_{2}\right)_{11} \mathrm{NH}_{2} \cdot \mathrm{HCl}\right)$ を $03 \times 10^{-2} \mathrm{~mol} / l$ の 範囲内で添加した。本研究での懸濁粒子濃度および空 気透過法で測定した各試料粒子の比表面積をもとに, 添加界面活性剂量と全㿟濁粒子表面を単分子層で覆う

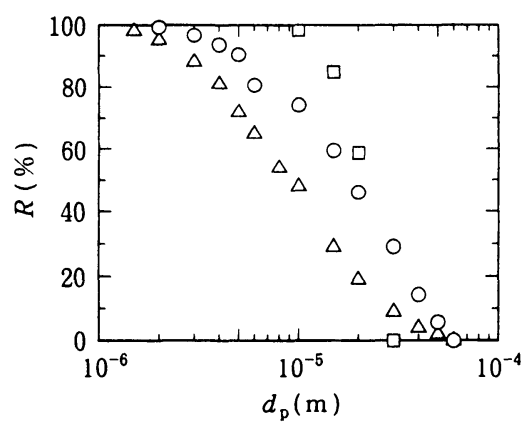

Fig. 1 Particle size distribution of raw particles

$\bigcirc$ : Soda-lime glass,

$\triangle$ : Calcium carbonate,

$\square$ : Polyethylene

に必要な界面活性剂量との関係を考えると, $3 \times 10^{-2}$ $\mathrm{mol} / l$ の条件での添加界面活性剂量は, 全粒子表面 を単分子層で覆うに必要な界面活性剂量の約 260 1700 倍に相当する。ここで, 両界面活性剂の 1 分子 当たりの吸着占有面積を $30 \AA^{212,13)}$ と仮定した。

\section{1.2 造柆実験}

造粒実験を以下の手順で行った。最初に, 架橋液 体である無極性のドデカン $\left(\mathrm{C}_{12} \mathrm{H}_{28}, \rho_{\mathrm{d}}=7.42 \times 10^{2}\right.$ $\mathrm{kg} / \mathrm{m}^{3}$, at $30^{\circ} \mathrm{C}$ ) を, 超音波摚拌器 (SHARP 製, UT-105H）を用いて $50 \mathrm{~cm}^{3}$ の分散媒中でエマルショ ン化し，それと同時に試料粒子を内径 $7 \mathrm{~cm}$ の擋找槽 造粒器内の分散媒中に入れて憗濁させた。この時間 を 10 分間とした。造粒器は既報 ${ }^{3)}$ で用いたものと同 じである。ドデカンのエマルション化を, 分散媒容 積 1 に対しドデカン容積を $0.06 \sim 0.12$ の範冊内で変 えて行った。これにより，造粒時のドデカン容積の全 愳濁粒子容積に対する比である架橋液体添加率 $r$ を, 0.17〜0.5 と変化させた。エマルション化されたドデ カン滴の粒子径分布を Fig. 2 に示す。ドデカン滴の $50 \%$ 粒子径は 3 $5 \mu \mathrm{m}$ となり, 添加界面活性剂濃度 の違いによる滴径への影響はほとんど見られなかっ た。

次に, ドデカンエマルションを注射器を使って造粒 


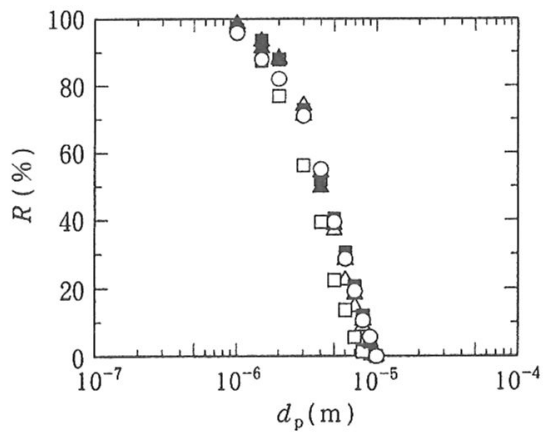

Fig. 2 Particle size distribution of dodecane droplets

$O$ : Non-addition of surface active agent,

$\triangle: C_{\text {ole }}=10^{-4} \mathrm{~mol} / l$,

$\Delta: C_{\text {ole }}=3 \times 10^{-2} \mathrm{~mol} / l$,

$\square: C_{\text {dod }}=10^{-4} \mathrm{~mol} / l$,

$\square: C_{\text {dod }}=3 \times 10^{-2} \mathrm{~mol} / l$

器内に注入して, 10 分間の造粒操作を行っだ。造粒 時の摚拌速度を $25 \mathrm{~s}^{-1}$, 造粒器内温度を $30^{\circ} \mathrm{C}$, 造粒 器内の全愁濁液量を $490 \mathrm{~cm}^{3}$ とした。分散媒中での試 料粒子の容積濃度 $C_{\mathrm{p}}$ を $1.25 \sim 3.75 \mathrm{vol} \%$ とした。造 粒現象が起こる場合, 架橋液体添加後 $3 \sim 5$ 分間でペ レット状造粒粒子となり, 造粒時間 10 分間以上での 造粒粒子径の増大は小さかった。

\section{1.3 試料粒子の造粒性の評価}

本研究で行った全ての実験条件で造粒現象が起こる わけではなく, また, 得られる造粒粒子は多種類の試 料粒子を含んだ複合造粒粒子となっている場合が多い と考えられる。このような状況下での各試料粒子の造 粒性の評価を, 以下の方法で行った。

10 分間の造粒操作後, 造粒器内の酳濁液を $3 \mathrm{~cm}^{3}$ 採取してシャーレに入れ, 残りの懸濁液を底部に $100 \mathrm{mesh}$ （目開き $147 \mu \mathrm{m}$ ）の篩をつけた円筒型脱水 器内に注ぎ, 通気脱水により造粒粒子を篩上に分離し た。分離された造粒粒子の外観の例を Fig. 3 に示す。 分離された造粒粒子中のドデカンをへキサン洗浄によ り除去し, 残った固体粒子を絶乾した。この固体粒子 中に炭酸カルシウム粒子が含まれている場合には, こ れを $2 \mathrm{~mol} / l-\mathrm{HCl}$ 水溶液中に入れ，そのときの溶解 質量を炭酸カルシウム粒子質量とした。ガラス粒子と ポリエチレン粒子の質量を, $\mathrm{HCl}$ 水溶液中で溶解せ ずに残った固体粒子の密度測定の結果を使って算出し た。測定された各試料粒子の質量をその密度で割るこ とにより, 造粒粒子中に含まれていた各試料粒子の容 積を求めた。造粒粒子の分離の際に 100 mesh 篩を通

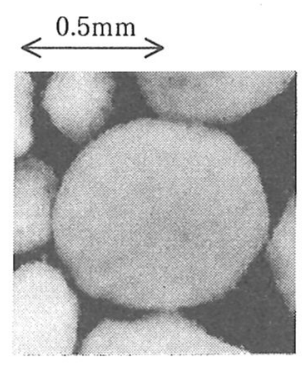

(a)

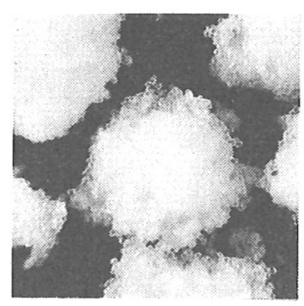

(c)

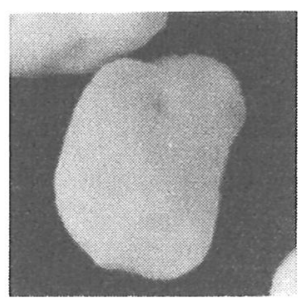

(b)

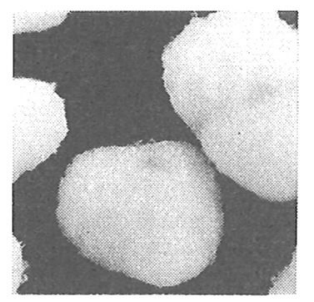

(d)
Fig. 3 Photographs of agglomerates made of various raw particles

(a) Soda-lime glass, $C_{\mathrm{p}}=1.25 \mathrm{vol} \%$, $r=0.5, C_{\mathrm{dod}}=10^{-3} \mathrm{~mol} / l$

(b) Calcium carbonate, $C_{\mathrm{p}}=1.25 \mathrm{vol} \%$, $r=0.5, C_{\text {ole }}=3 \times 10^{-3} \mathrm{~mol} / l$

(c) Polyethylene, $C_{\mathrm{p}}=1.25 \mathrm{vol} \%, r=0.5$, No addition of surface active agent

(d) Soda-lime glass-Calcium carbonatePolyethylene, $C_{\mathrm{p}}=3.75 \mathrm{vol} \%, r=0.33$, $C_{\text {dod }}=3 \times 10^{-3} \mathrm{~mol} / l$

過して脱水液中に含まれる各試料粒子の容積も, 上記 とほぼ同様の手順により求められた。試料粒子 $i$ の造 粒性を, Eq. (1) で定義される試料粒子 $i$ の造粒粒子 中への回収率 $\alpha$ により評価した。

$$
\alpha=\left(\frac{V_{\mathrm{oi}}}{V_{\mathrm{ti}}}\right) \times 100
$$

ここで $V_{\mathrm{oi}}$ は, $100 \mathrm{mesh}$ 篩上に分離された試料粒子 $i$ の容積, $V_{\mathrm{ti}}$ は篩上, 脱水液中に含まれる試料粒子 $i$ の全容積である。

造粒操作後に採取した $3 \mathrm{~cm}^{3}$ の孫濁液中に含まれる 造粒粒子の粒子径測定を, 万能投影機 (OLYMPUS 製）を使って以下のように行った。Feret 径が 100 $\mu \mathrm{m}$ 以上となる造粒粒子を 50 個無作為抽出し, それ らの Feret 径を測定してその算術平均値 $d_{\text {aa }}$ を求め た。粒子径測定を Feret 径が $100 \mu \mathrm{m}$ 以上の造粒粒子

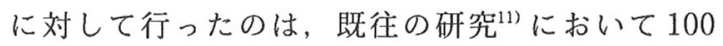
mesh の篩上に分離された造粒粒子群の最小平均粒子 径が約 $100 \mu \mathrm{m}$ であったことによる。このような方法 
により $d_{\text {a }}$ を求めたのは，造粒粒子の強度が充分でな く，このため篩を使っての固液分離操作において造粒 粒子が変形し, 元の造粒粒子径の測定が困難となる場 合が見られたためである。 $d_{\mathrm{aa}}$ を篩上に分離された造 粒粒子群の平均粒子径に対応するものと仮定し， $\alpha$ と $d_{\text {aa }}$ との関係についても検討した。

\section{2 界面物性測定}

$30 \pm 1{ }^{\circ} \mathrm{C}$ における架橋液体/分散媒間の界面張力 $\gamma_{\text {ow }}$ の測定を, 眯滴法. ${ }^{314}$ により行った。分散媒中で 出口が上方を向いた外径 $0.4 \mathrm{~mm}$ の注射針先端より架 橋液体を出して滴を作り，10 分間経過後の架橋液体 滴の形状より $\gamma_{\text {ow }}$ を算出した。

接触角 $\theta$ の測定を以下のように行った。造粒現象を 検討する際の接触角の測定法としては, 造粒粒子中 の架橋液体の接触角を測定する直接測定法 ${ }^{3.4}$ ) が最良 と考えられるが，同法による測定が全実験条件で可 能なのはポリエチレン粒子に対してのみであった。 ガラス粒子の場合には，接触角が $90^{\circ}$ 前後になる 之, 透明なガラス粒子と液体架橋の凸面の区別がつき にくいこと, また, 炭酸カルシウム粒子の場合には, 明確な液体架橋そのものを見つけることが困難であっ た。このようなことからこれら二つの試料粒子に 対する接触角としては, 同じ材質の平板を用いての Hanging drop 法 ${ }^{2}$ により測定された值を用いること にした。

接触角の直接測定法を, 10 分間の造粒操作後, 造 粒器内から採取した照濁液中の造粒粒子を用いて行っ た。Hanging drop 法による測定では接触角計 (協和 界面科学製、 CA-A 型) を用いた。平板として，ガラ ス粒子と同じ材質のスライドガラス，および $\mathrm{CaCO}_{3}$ 純度ほぼ $100 \%$ の石灰石平板を研磨したものを用い た。スライドガラス面の洗浄 ${ }^{15)}$ を，中性洗剂による 洗浄後, 流下水道水中および蒸留水中で充分な洗浄を 行うことにより行った。石灰石平板面の洗浄を, 研磨 後, 流下水道水中および蒸留水中で充分な洗浄を行う ことにより行った。測定では，まず $30 \pm 1{ }^{\circ} \mathrm{C}$ に保た れた分散媒中に平板の測定平面を浸し，それと同時に 出口が上方を向いた注射針の先端より架橋液体滴を出 して, 10 分間静置させた。その後, 架橋液体滴を試 料平板の測定平面に付着させ, 付着液滴の形状に変化 が見られなくなってから，接触角を測定した。

分散媒中の試料粒子, 架橋液体滴のゼー夕電位 $\zeta$ を, 顕微鏡電気泳動法 ${ }^{4)}$ により $27 \sim 30^{\circ} \mathrm{C}$ の条件で測 定した。測定は, 分散媒中で 10 分間㦟濁された後の 試料粒子, 架橋液体滴に対して行われた。

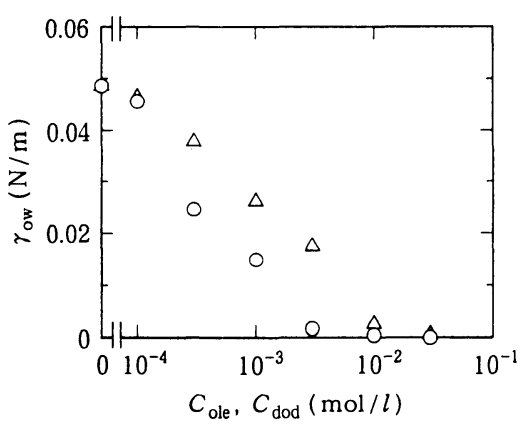

Fig. 4 Interfacial tension of dodecane/dispersion medium system

Additive surface active agent :

$\mathrm{O}$ : Sodium oleate ;

$\triangle$ : Dodecylamine hydrochloride
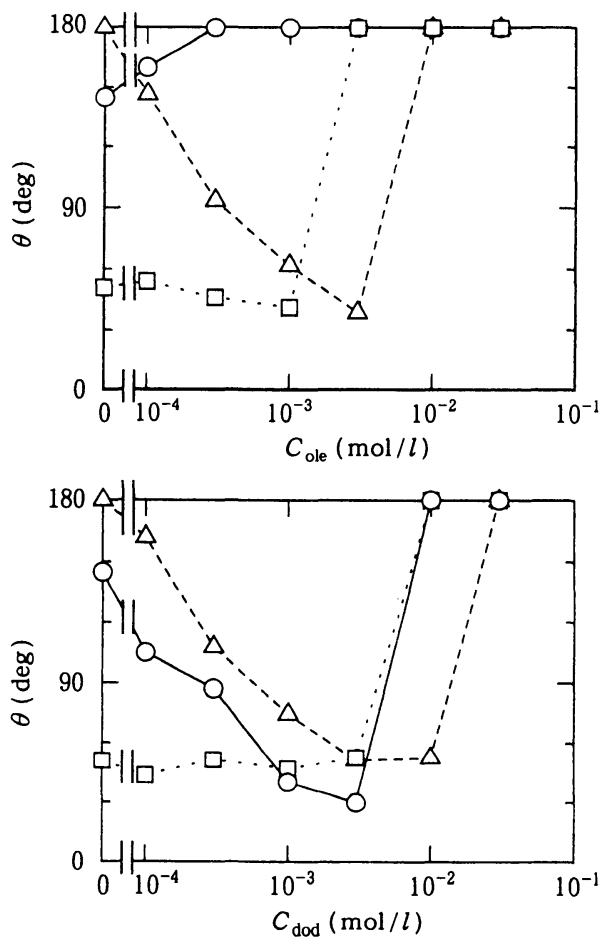

Fig. 5 Change of contact angle with concentration of additive surface active agent

$O$ : Soda-lime glass,

$\triangle$ : Calcium carbonate,

$\square$ : Polyethylene

\section{3．実験結果および考察}

\section{1 界面物性への添加界面活性剂濃度の影響}

Figs. 4,5 に, 架橋液体／分散媒間の界面張力 $\gamma_{\text {ow }}$, 
架橋液体の試料粒子に対する接触角 $\theta$ の測定結果を示 す。

界面張力 $\gamma_{\text {ow }}$ は, 添加界面活性剂濃度の増大につれ て減少した。接触角 $\theta$ は, ガラス粒子に対する場合に は, 添加界面活性剂種により変化の様子が大きく異な った。オレイン酸ナトリウム添加下では, 多くの場合 にドデカン滴がガラス面上にほぼ球形で存在するよう になり，このとき $\theta$ を $180^{\circ}$ とした。ドデシルアミ ン塩酸塩添加下では, 添加濃度 $C_{\mathrm{dod}} \leqq 3 \times 10^{-3} \mathrm{~mol} / l$ の範囲内では, $\theta$ は $C_{\text {dod }}$ の増大につれて減少し, ガ ラス面に対するドデカンの濡れ性が増した。しかし, $10^{-2} \mathrm{~mol} / l \leqq C_{\mathrm{dod}}$ では $\theta=180^{\circ}$ となった。炭酸カル シウム粒子, ポリエチレン粒子に対する $\theta$ は, 両界面 活性剂添加の場合ともに類似した変化を示した。接触 角 $\theta$ は, Young-Dupréの式に示されるように, ドデ カンの付着に関係する三つの界面エネルギーの釣り合 いから決定される。しかし, 測定可能なのはドデカ ン/分散媒間の界面張力 $\gamma_{\text {ow }}$ のみであることから,

Fig. 5 中の $\theta$ の変化パターンを明確に説明すること はできない。

$\gamma_{\text {ow }}, \theta$ の変化に最も影響を与えているものとして, 分散媒中の添加界面活性剂の固体粒子表面およびド デカン滴表面への吸着が考えられる。Fig. 6 は, 分散

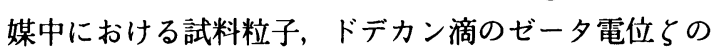
測定結果を示したものである。分散媒中にオレイン酸 ナトリウムが添加されている場合, 全ての試料粒子お よびドデカン滴のらは負の值となった。特に, 界面活 性剂無添加の条件では正に帯電する炭酸カルシウム粒

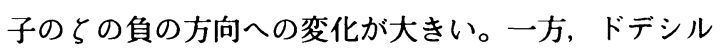
アミン塩酸塩添加下では, ほとんどの った。この場合も, 界面活性剂無添加の分散媒中では 負の值となるガラス, ポリエチレン粒子の $\zeta$ の, 正の 方向への変化が大きくなっている。

オレイン酸ナトリウム, ドデシルアミン塩酸塩は水 中で電離し, さらに加水分解によりそれぞれ次のよう な平衡関係が成立している。

$$
\begin{aligned}
& \mathrm{C}_{17} \mathrm{H}_{33} \mathrm{COOH}+\mathrm{H}_{2} \mathrm{O} \rightleftarrows \mathrm{C}_{17} \mathrm{H}_{33} \mathrm{COO}^{-}+\mathrm{H}_{3} \mathrm{O}^{+} \\
& \mathrm{C}_{12} \mathrm{H}_{25} \mathrm{NH}_{2}+\mathrm{H}_{2} \mathrm{O} \rightleftarrows \mathrm{C}_{12} \mathrm{H}_{25} \mathrm{NH}_{3}^{+}+\mathrm{OH}^{-}
\end{aligned}
$$

Eqs. (2), (3) の室温での平衡定数はそれぞれ $10^{-516)}$, $4.3 \times 10^{-417)}$ である。一方, 造粒操作前の試料粒子の 予備擋拌後の懸濁液中の $\mathrm{pH}$ は, オレイン酸ナトリウ ム添加時では 8 10.5, ドデシルアミン塩酸塩添加時 では $6 \sim 9$ である。これらの $\mathrm{pH}$ 值と上記の平衡定数

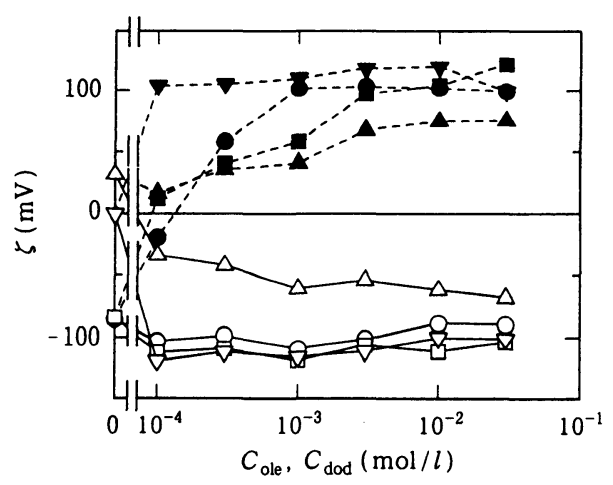

Fig. $6 \zeta$-potential of raw particle and dodecane droplet

Additive surface active agent :

Sodium oleate

$\bigcirc$ : Soda-lime glass,

$\triangle$ : Calcium carbonate,

$\square$ : Polyethylene, $\nabla$ : Dodecane Additive surface active agent :

Dodecylamine hydrochloride

: Soda-lime glass,

$\Delta$ : Calcium carbonate,

$\square$ : Polyethylene, $\boldsymbol{\nabla}$ : Dodecane

より, 造粒時においては添加界面活性剂の一部はド デカン滴中に溶解するものの, 分散媒中では界面活 性剂のほとんどは $\mathrm{C}_{17} \mathrm{H}_{33} \mathrm{COO}^{-}, \mathrm{C}_{12} \mathrm{H}_{25} \mathrm{NH}_{3}^{+}$として存 在することになる。すなわち, 分散媒中への界面活 性剂の添加による $ら$ の変化は, 主に $\mathrm{C}_{17} \mathrm{H}_{33} \mathrm{COO}^{-}$, $\mathrm{C}_{12} \mathrm{H}_{25} \mathrm{NH}_{3}^{+}$の試料粒子およびドデカン滴表面への吸着 により起こっているものであり， $\gamma_{\text {ow }}, \theta$ の変化はこ れらの界面活性剂イオンの吸着層の存在による影響と 言える。

Fig. 7 に, Figs. 4, 5 の結果を使って算出した付着 張力 $\gamma_{\text {ow }} \cos \theta$ を示す。既報 ${ }^{3}{ }^{4)}$ で示したように, 湿 式造粒による平衡造粒粒子径 $d_{\mathrm{ae}}$ とこれに影響する 種々の要因との関係は Eq. (4) で表わされ, べき数 $a$ として1に近い值が得られている。

$$
d_{\mathrm{ae}} \propto\left\{s p\left(6 \frac{1-\varepsilon}{\varepsilon} \frac{\gamma_{\mathrm{ow}} \cos \theta}{d_{\mathrm{ps}}}\right)\right\}^{\mathrm{a}}
$$

ここで, $\varepsilon, s$ は造粒粒子内の空隙率および架橋液体 の飽和度であり, $p$ は入口吸引圧から毛管吸引压を算 出するための係数, $d_{\mathrm{ps}}$ は試料粒子の比表面積球相当 径である。Eq. (4) より湿式造粒においては, 造粒粒 子径は付着張力 $\gamma_{\text {ow }} \cos \theta$ が正で, その値が大きくな るにつれて增大することになる。一方， $\theta>90^{\circ}$ と なって付着張力が負の場合, 造粒現象は起こらない。 

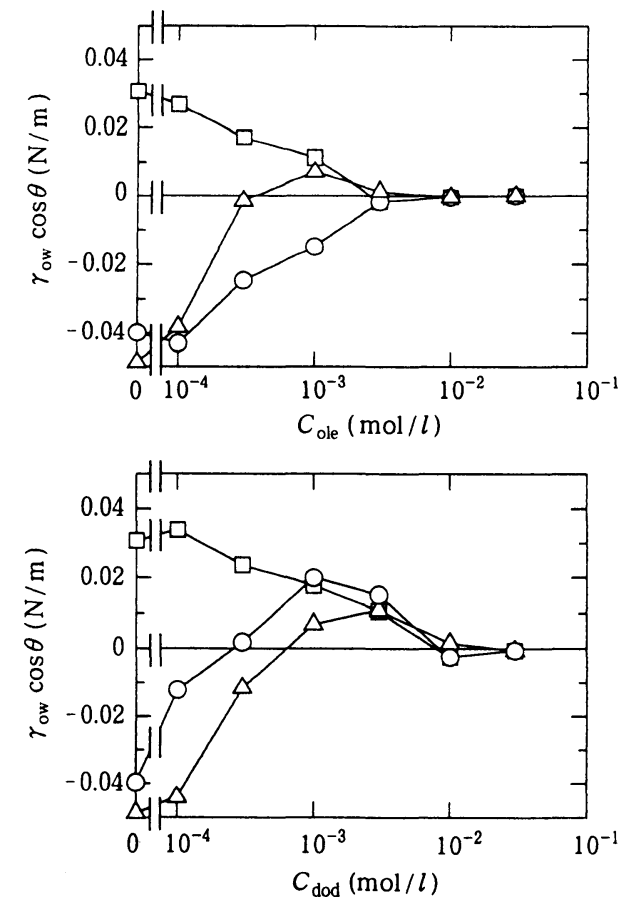

Fig. 7 Change of adhesion tension with concentration of additive surface active agent

$\mathrm{O}$ : Soda-lime glass,

$\triangle$ Calcium carbonate,

$\square$ : Polyethylene

Fig. 7 において，付着張力は試料粒子の種類により それぞれ異なる変化を示している。これらの付着張力 值の違いを利用することにより，希望する粒子の選択 的造粒が可能と考えられる。

\section{2 湿式造粒への付着張力の影策}

Fig. 8 に，分散媒中に 1 種類の試料粒子を暞濁させ て湿式造粒を行った場合の，造粒粒子中への試料粒子 の回収率 $\alpha$, 平均造粒粒子径 $d_{\mathrm{ag}}$ の測定結果を示す。 造粒現象は付着張力が正の值となる場合に起こり, 全 体として $\alpha, d_{\text {å }}$ は付着張力が正でその値が大きいほ ど増大する傾向が見られる。オレイン酸ナトリウム添 加下で炭酸カルシウム粒子を造粒させた場合におい て, 添加濃度 $C_{\text {ole }}$ が $10^{-3} \mathrm{~mol} / l$ と $3 \times 10^{-3} \mathrm{~mol} / l$ の 条件で, Fig. 7 に示す付着張力と $\alpha$ の大小関係が逆 転している結果が得られている。この原因の一つとし て, 湿式造粒時と界面物性測定時では, 固体表面への 吸着量の違いにより液中の残留オレイン酸ナトリウム 濃度が異なり，その結果として界面物性測定值から算 出される付着張力の値か，造粒時の付着張力の值を正 確には再現していないことが考えられる。Fig. 1 に
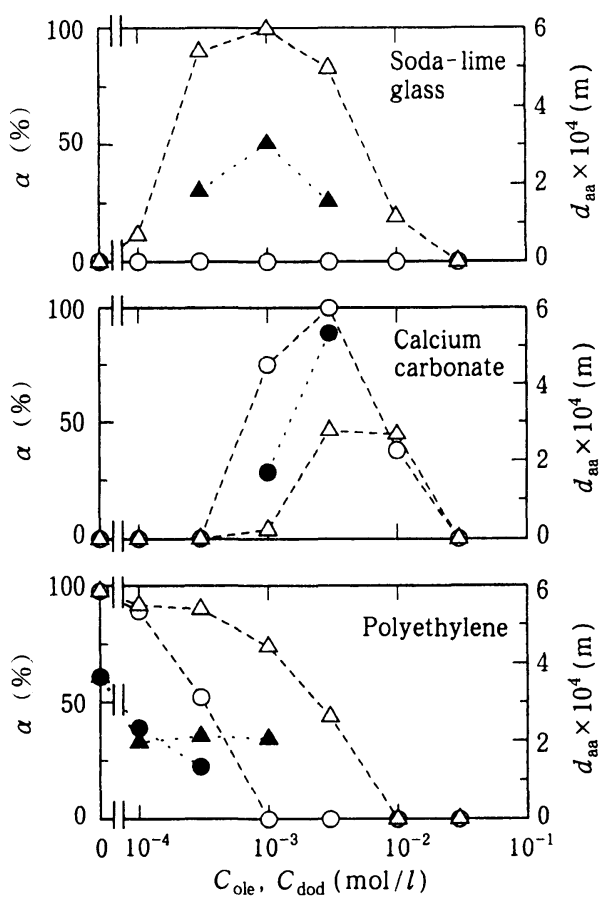

Fig. $8 \alpha$ and $d_{\text {a }}$ by wet agglomeration in a suspension of particles of one material $\left(C_{\mathrm{p}}=1.25 \mathrm{vol} \%, r=0.5\right)$

Additive surface active agent:

Sodium oleate

$\bigcirc: \alpha, \bigcirc: d_{\text {aa }}$

Additive surface active agent:

Dodecylamine hydrochloride

$\triangle: \alpha, \boldsymbol{\Delta}: d_{\text {ва }}$

示すように，他の 2 粒子に比較して粒子径が小さく比 表面積の大きい炭酸カルシウム粒子の場合には, この ことがより起こりやすいと言える。 $\alpha$ が 0 以上となる ときでも $d_{\mathrm{aa}}$ の值がプロットされていない場合が見ら れるが, これらは造粒粒子のペレット化が充分でな く, Feret 径の測定が困難であったことによる。この ことは，これ以後の図においても同様である。一方， 付着張力が負の場合, 造粒現象が起こらず, 㦟濁液の ほぼ全てが $100 \mathrm{mesh}$ 篩を通過し， $\alpha$ は 0 に近い值と なった。すなわち，本研究で用いた試料粒子の湿式造 粒は，付着張力の正負およびその大きさに強く影響さ れていることが分る。

\section{3 多種粒子懸濁液中での湿式造粒}

分散媒中に 2 種類， 3 種類の試料粒子を懸濁させた 液中で湿式造粒を行い，選択的造粒に及ぼす付着張力 の影響を検討した。

Figs. 9, 10 に， 2 種類の試料粒子を同量ずつ懸濁さ 

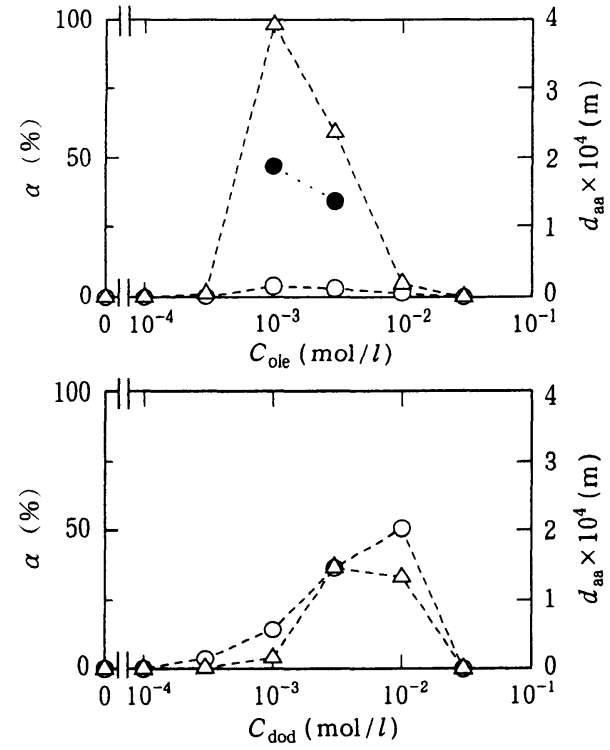

Fig. $9 \alpha$ and $d_{\text {a }}$ by wet agglomeration in a suspension of particles of soda-lime glass and calcium carbonate $\left(C_{\mathrm{p}}=2.5 \mathrm{vol} \%, r=0.25\right)$

$\mathrm{O}: \alpha$ of soda-lime glass,

$\triangle: \alpha$ of calcium carbonate,

$: d_{\mathrm{aa}}$

せ $C_{\mathrm{p}}=2.5 \mathrm{vol} \%$ とした液中で湿式造粒を行った場合 の, $\alpha, d_{\mathrm{aa}}$ の測定例を示す。ガラスー炭酸カルシウ 么㦟濁液に対する結果を示した Fig. 9 では， $C_{\text {ole }}=$ $10^{-3} \mathrm{~mol} / l$ において, 炭酸カルシウム粒子の $98 \%$ が 造粒粒子中に回収され，ガラス粒子は $96 \%$ が脱水液 中に分離されている。すなわち, 炭酸カルシウム粒子 のみの選択的造粒が良好に行われ, 両試料粒子がほぼ 分離されたことになる。 $C_{\mathrm{ole}}=10^{-3} \mathrm{~mol} / l$ の条件で は, 付着張力は炭酸カルシウム粒子に対して正, ガラ ス粒子に対しては負となり，このことが炭酸カルシウ 厶粒子の選択的造粒を良好に行わせた最大の原因であ る。ドデシルアミン塩酸塩添加の条件では, 両試料粒 子に対する付着張力の変化は類似している。このた め, 付着張力が共に正となる場合には, 両試料粒子と も造粒され，ほぼ同じ $\alpha$ の值を示した。このとき, 個 個の造粒粒子は両試料粒子を含む複合造粒粒子となっ ていることが考えられる。

Fig. 10 のガラスーポリエチレン㦟濁液に対する結 果では, $C_{\text {ole }}=0 \sim 3 \times 10^{-4} \mathrm{~mol} / l$ の条件において, ポ リエチレン粒子が選択的に造粒され, 両試料粒子が造 粒粒子中と脱水液中に良く分離されている。一方, ド テシルアミン塩酸塩添加下では, $C_{\mathrm{dod}}=0 \mathrm{~mol} / l$ の条
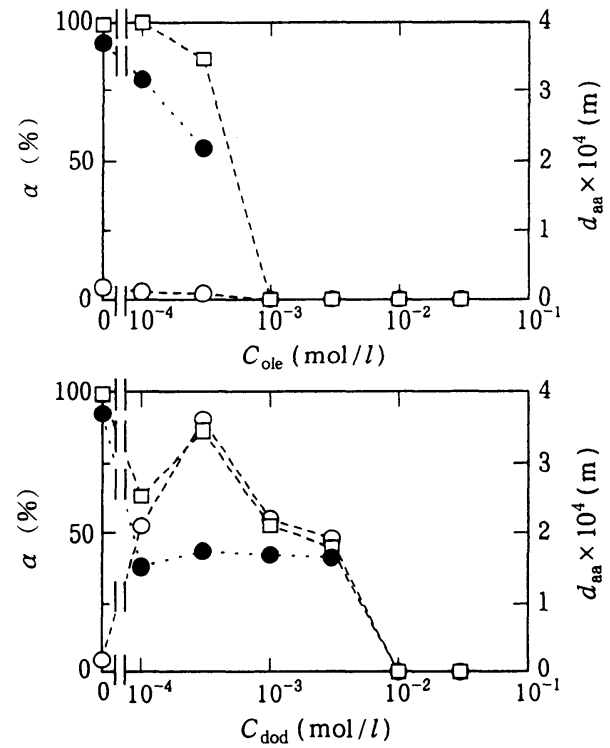

Fig. $10 \alpha$ and $d_{\text {aa }}$ by wet agglomeration in a suspension of particles of soda-lime glass and polyethylene $\left(C_{\mathrm{p}}=2.5 \mathrm{vol} \%, r=0.25\right)$ $O: \alpha$ of soda-lime glass, $\square: \alpha$ of polyethylene, $: d_{\mathrm{aa}}$

件でのみポリエチレン粒子が選択的に造粒されてい る。これらの場合には，いずれもポリエチレン粒子に 対する付着張力が正, ガラス粒子に対する付着張力が 負となっている。付着張力が共に正の場合には, 雨試 料粒子に対する $\alpha$ の值がほぼ同じとなった。

Figs. 11, 12 に， 3 種類の試料粒子を同量ずつ懸濁 させ $C_{\mathrm{p}}=3.75 \mathrm{vol} \%$ とした液中で, 架橋液体添加率 $r$ を $0.17,0.25,0.33$ と変えて湿式造粒を行った場合の $\alpha$ の測定結果を示す。Figs. 11, 12 ともに, 各試料粒 子の $\alpha$ が大きな值となる $C_{\text {ole }}, C_{\text {dod }}$ 条件は， 1 種粒子 㦟濁液の場合に類似している。しかし, ポリエチレン 粒子に対する場合のように, 1 種粒子㦟濁液中での $\alpha$ は $C_{\text {ole }}, C_{\text {dod }}$ の增大と共に単調堿少するが, 3 種粒子 緜濁液中では $C_{\text {ole }}, C_{\text {dod }} \geqq 3 \times 10^{-4} \sim 3 \times 10^{-3} \mathrm{~mol} / l$ で $\alpha$ が再び増加に転じるような, 1 種粒子綮濁液の場合 には起こらない現象も見られる。この原因としては, 多種粒子㦟濁液中での湿式造粒は, 個個の懸濁粒子の 架橋液体滴に対する需れ性のみでなく，懸濁粒子同士 の相互作用に基つく付着性にも影響されていることが 考えられる。Figs. 11，12では, 架橋液体添加率 $r$ が 大きくなるにつれて, 造粒されやすい試料粒子の $\alpha$ が 増大する傾向が見られる。これは Eq. (4) から分るよ 

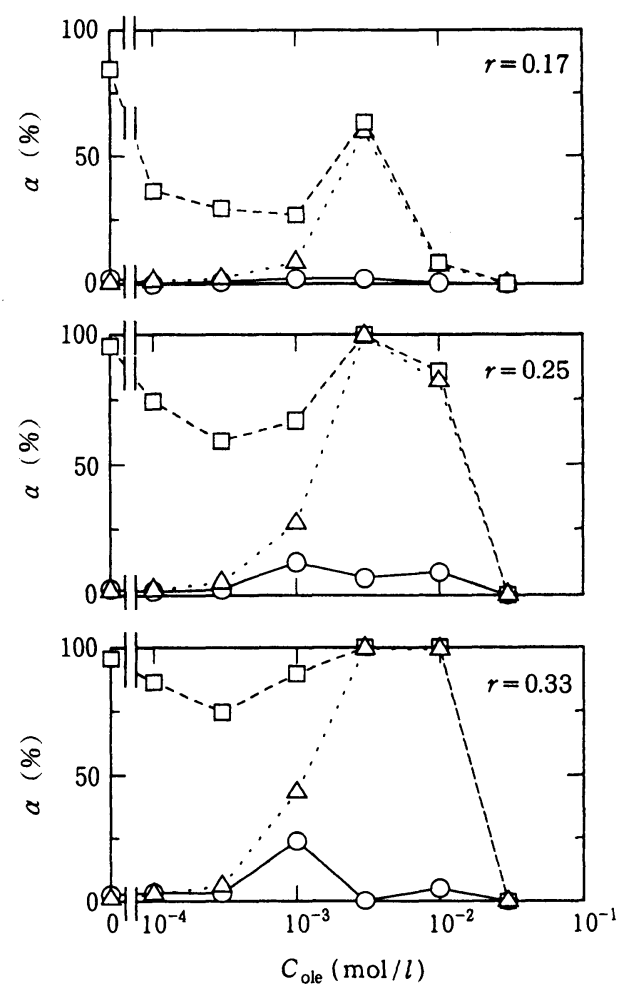

Fig. $11 \alpha$ by wet agglomeration in a suspension of particles of three materials $\left(C_{\mathrm{p}}=3.75 \mathrm{vol} \%\right)$

Additive surface active agent :

Sodium oleate

: Soda-lime glass,

$\triangle$ : Calcium carbonate,

$\square$ : Polyethylene

うに, $r$ の増大につれて造粒粒子内の架橋液体飽和度 $s$ が增して造粒粒子径が増大し， 100mesh 篩上に分 離される造粒粒子量が増すためと考えられる。3 種粒 子憼濁液中での湿式造粒による平均造粒粒子径 $d_{\text {aa }}$ は, $0.11 \sim 0.60 \mathrm{~mm}$ となり, $r$ の増大につれて $d_{\mathrm{aa}} も$ 増大する傾向が見られた。

Figs. 9 12 の結果より, 多種類の試料粒子を含む 懸濁液中での湿式造粒においても，各試料粒子の造粒 現象への関与の仕方は, 基本的には 1 種類の粒子愻濁 液中での湿式造粒の場合とほぼ同じであると言える。 これより，適した造粒条件を選ぶことにより，選択的 湿式造粒による水中の混合微粒子の分離は可能である と言える。

\section{4. 結言}

$10^{-2} \mathrm{~mol} / l-\mathrm{NaCl}$ 水溶液を分散媒として極性および
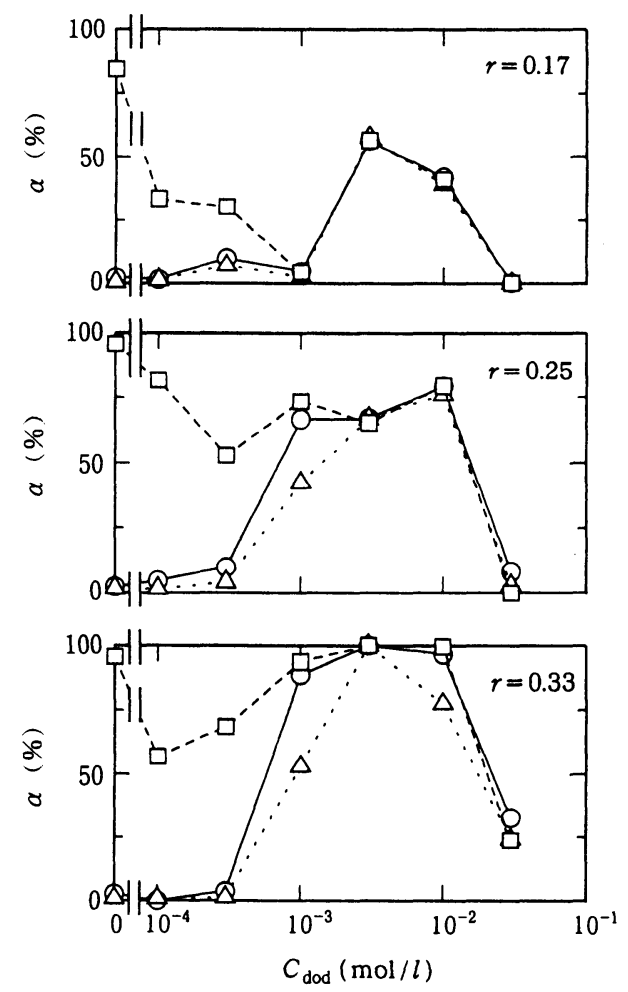

Fig. $12 \alpha$ by wet agglomeration in a suspension of particles of three materials $\left(C_{\mathrm{p}}=3.75 \mathrm{vol} \%\right)$

Additive surface active agent : Dodecylamine hydrochloride

$\mathrm{O}$ : Soda-lime glass,

$\triangle$ : Calcium carbonate,

$\square$ : Polyethylene

無極性物質よりなる多種類の粒子を含む㦟濁液中で, 無極性のドデカンを架橋液体として湿式球形造粒につ いて検討した。分散媒中への添加界面活性剂として, 極性のオレイン酸ナトリウムまたはドデシルアミン塩 酸塩を用いた。実験の結果，以下の結論を得た。

1) 極性物質で親水性表面を持つソーダ石灰ガラス粒 子，炭酸カルシウム粒子は，粒子表面への添加界面 活性剂の適度な吸着により，ドデカンに対する濡れ 性が大きく改善され，それにつれて両粒子の湿式造 粒が容易となった。無極性物質で疎水性表面を持っ ポリエチレン粒子は, 分散媒中への界面活性剂が無 添加の条件でドデカンに対する濡れ性が良く，添加 界面活性剂濃度が $10^{-3} \mathrm{~mol} / l$ 以下までの条件では, 界面活性剂の添加によりドデカンに対する需れ性は ほとんど影響されなかった。

2 ) 多種類の粒子を含む㦟濁液中において, 個個の粒 


\section{Nomenclature}

$a \quad$ : power exponent in Eq. (4)

$C_{\text {dod }}$ : concentration of dodecylamine hydrochloride

$C_{\text {ole }}$ : concentration of sodium oleate

$C_{\mathrm{p}}$ : concentration of raw particle in dispersion medium

$d_{\mathrm{aa}}$ : arithmetic mean diameter of agglomerates

$d_{\text {ae }}$ : equilibrium agglomerate diameter

$d_{\mathrm{d}}$ : diameter of dodecane droplet

$d_{\mathrm{p}}$ : diameter of raw particle

$d_{\mathrm{ps}}$ : specific surface diameter of raw particle

$d_{\mathrm{p} 50}: 50 \%$ diameter of raw particle

$p \quad$ : coefficient

$R \quad$ : cumulative oversize percent
$(-) \quad r \quad$ : addition ratio of bridging liquid $\quad(-)$

$s \quad$ : saturation degree $(-)$

$V_{\text {oi }}$ : volume of raw particle $i$ separated on 100mesh wire netting $\left(\mathrm{m}^{3}\right)$

$V_{\mathrm{ti}}:$ total volume of raw particle $i \quad\left(\mathrm{~m}^{3}\right)$

$\alpha$ : recovery ratio of raw particles (\%)

$\gamma_{\text {ow }}:$ interfacial tension of dodecane/dispersion medium system (N/m)

$\varepsilon \quad:$ porosity

$\zeta \quad$ : zeta potential

$\theta \quad$ : contact angle

$\rho_{\mathrm{d}} \quad$ : density of dodecane

$\rho_{\mathrm{p}}$ : density of raw particle

\section{References}

1) Capes, C. E. and J. P. Sutherland: "Formation of Spheres from Finely Divided Solids in Liquid Suspension", Ind. Eng. Chem., Process Design and Develop., 6, 146-154 (1967)

2 ) Takenaka, H., Y. Kawashima, M. Nakashima and Y. Kurachi : "Interfacial Chemical Properties of Powder and Spherical Agglomeration in Liquid”, J. Soc. Powder Technol., Japan, 16, 681-686 (1979)

3 ) Takase, H. and S. Shojiguchi : "Equilibrium Agglomerate Diameter in Wet Spherical Agglomeration", J. Soc. Powder Technol., Japan, 37, 253-259 (2000)

4 ) Takase, H. and S. Shojiguchi : "Effect of Capillary Suction Potential on Agglomeration of Coal in Water", J. Min. Mat. Process. Inst. Japan, 117, $117-122$ (2001)

5 ) Kawashima, Y. and C. E. Capes: "An Experimental Study of the Kinetics of Spherical Agglomeration in a Stirred Vessel" ${ }^{n}$, Powder Technology, 10, 85-92 (1974)

6 ) Rao, T. C. and M. Vanangamudi : "Quantitative Studies on the Coal-Oil Agglomeration Process", Powder Technology, 40, 195-205 (1984)

7 ) Hirajima, T., M. Tsunekawa and T. Takamori : "Effect of Compaction Process on Agglomerates Growth", J. Min. Mat. Process. Inst. Japan, 108, 146-152 (1992)

8 ) Capes, C. E., A. E. Mcllhinney and R. D. Coleman : "Beneficiation and Balling of Coal", Trans. SME/AIME, 247, 233-237 (1970)

9 ) Armstrong, L. W., A. R. Swanson and S. K. Nicol:
"A Pilot-Scale Treatment of Coal Preparation Plant Effluent by the Selective Agglomeration Process", CIM Bulletin, November, 89-92 (1979)

10) Takase, H., K. Ikeda and M. Sugimoto: "Study on the Deashing of Coal by the Oil Agglomeration Process The Effect of the $\mathrm{pH}$ of the Disperse Medium on Deashing Efficiency - ", J. Soc. Powder Technol., Japan, 30, $101-107$ (1993)

11) Takase, H. and S. Sugimoto: "Influence of Agglomerate Size on Drainage of Packed Bed of Coal Agglomerates", Kagaku Kogaku Ronbunshu, 15, 238-245 (1989)

12) Mizuniwa, T., K. Iwano, I. Matsuoka and Y. Hotta : "Spectrophotometric Determination of Sodium Oleate with Nile Blue - Determination of the Amounts of Sodium Oleate Adsorbed on Nonsulfide Minerals - ", J. Min. Mat. Process. Inst. Japan, 93, 435-439 (1977)

13) Nishi, I., I. Imai and M. Kasai : "Kaimenkasseizai Benran”, p. 109, Sangyo Tosho, Tokyo (1960)

14) Nippon Kagakukai : "Shin Jikken Kagaku Kouza 18", pp. 78-79, Maruzen, Tokyo (1977)

15) Nippon Kagakukai : "Shin Jikken Kagaku Kouza 18”, pp. 95-96, Maruzen, Tokyo (1977)

16) Shimoiizaka, J. : "Some Problems on Nonsulfide Mineral Flotation", Fusen, 23, 23-37 (1976)

17) Gaudin, A. M. and T. G. Decker : "Contact Angles and Adsorption in the System Quartz-Water-Dodecane Modified by Dodecyl Ammonium Chloride", J. Colloid Interface Sci., 24, 151-158 (1967) 